\title{
Postharvest methyl jasmonic acid and hot water can reduce the internal breakdown and quality loss of apricot fruit at shelf life
}

\author{
Ezzat, A. \\ Department of Horticulture, Faculty of Agriculture, Kafelelsehikh University, Kafr El-Shaikh, Egypt \\ Author for correspondence: ahmed.kassem@agr.kfs.edu.eg
}

\begin{abstract}
Summary: The aim of this study was to investigate the postharvest effect of methyl jasmonic acid (MJ) and hot water on internal break-down and quality loss of apricot fruit under shelf life conditions. Cultivar Flavor cot apricot fruit were used to treat with water as control treatment, with 0.2 $\mathrm{mmol} / \mathrm{L} \mathrm{MJ}$ and with hot water $35^{\circ} \mathrm{C}$ for $5 \mathrm{~min}$. Fruit were stored at room temperature and were examined every 2 days for internal break-down and quality loss. Results showed that treated fruits with $\mathrm{MJ}$ and hot water showed the lowest weight loss and the highest firmness during all assessment times. Control fruits showed losing of customer acceptance from the day 2 of shelf life and then decreased dramatically to approximately loss all the acceptance at day 8. The SSC showed sever reduction in untreated fruit after day 6 at shelf life. Total phenol content reduced and polyphenol oxidase (PPO) increased in all assessment times for all treatments. Meanwhile MJ showed the best values for phenol content and lowest PPO activity. The results supported the idea of using some elicitors like methyl jasmonic and hot water treatments to enhance shelf life of apricot fruit.
\end{abstract}

Ezzat, A. (2020): Postharvest methyl jasmonic acid and hot water can reduce the internal break-down and quality loss of apricot fruit at shelf life. International Journal of Horticultural Science 2020, 26: 31-34. https://doi.org/10.31421/IJHS/26/2020/8003

Key words: methyl jasmonic acid, hot water, apricot, postharvest, shelf life, weight loss, firmness, total phenol

\section{Introduction}

Many seasonal and postharvest parameters can play essential roles for chilling injuries of apricot. Hungarian apricot harvest occurs during June and July, and this period is the available marketing period for large quantities (Ezzat et al., 2012).

Stone fruits including apricots are one of the most susceptible fruit disorder like, internal breakdown and fruit decays caused by several fungus like Monilinia spp. (Holb, 2004ab; Holb \& Schnabel, 2007, 2008; Holb \& Scherm, 2008; Amiri et al., 2009; Ezzat et al.,2013, 2014), Botrytis cinerea, Penicillium expansum, and Rhizopus stolonifer (Manganaris \& Crisosto, 2020). Fruit internal browning (IB), is one of the most important physiological disorder which develop in apricot fruit under low temperature especially under postharvest conditions. For that many experiment were conducted to examine many elicitors to reduce IB in apricot like salicylic acid and MAP in order to increase shelf life and fruit quality of apricot (Ezzat et al., 2013, 2014, 2017; Ezzat, 2018). The fruit browning was found to be related to activities of enzymes such as phenylalanine ammonia lyase (PAL) and polyphenol oxidase (PPO). PAL is an essential enzyme in the phenol biosynthesis and these phenols are oxidized by PPO to quinines, which polymerize into brown colour pigment (Cao et al., 2009; Wu et al., 2015; Wang et al., 2019).

The objective of this work was to study the postharvest influence of methyl jasmonic acid and hot water on internal break-down and quality loss of apricot fruit under shelf life storage.

\section{Materials and methods}

\section{Fruit sampling}

Apricot (Prunus armeniaca L.) cultivar (cv.) Flavor Cot at harvest maturity were harvested from local commercial farm in the north of Hungary. Fruit were selected to be in equal size and appearance. Fruit were stored at $25^{\circ} \mathrm{C}$ for one night then the treatments were applied.

\section{Treatments}

Fruit were cleaned by tap water and kept 3 hour to be dried at room temperature. Fruit were divided into 3 groups and as follow: Group A: fruit were stored in room temperature $25 \mathrm{C}$ for one day. Group B: fruit were treated with $0.2 \mathrm{mmol} / \mathrm{L}$ methyl jasmonic acid (MJ) and stored in room temperature for one day. Group C: fruit were treated with hot water $35^{\circ} \mathrm{C}$ for $5 \mathrm{~min}$ and then dried with air. Each group was divided into 3 subgroups (20 fruit per each), then added into plastic pages with small holes and stored in room temperature for 10 days.

Total acceptance, fruit firmness, soluble solid content (SSC) and weight loss

Sensory parameters were measured by five judges including, color of skin and flesh, texture, taste, appearance by visual and acceptability. The total quality scores were the following: 5, outstanding; 4, very good; 3 , good, 2 , poor edible; 1 , inedible. Fruit firmness was assessed on two fruit sides using DUROFEL Agrosta firmness tester and data were expressed as $\mathrm{kg} / \mathrm{cm}^{2}$. SSC 
was assessed by a refractometer in Brix (\%). Loss of fruit weight was measured by weight the fruits at the start of the trail and at the assessment time of investigation every 2 days. Weight loss was calculated as $\%$ of total weight lost.

\section{Internal browning $(I B)$}

50 fruits were examined to calculate the fruit number developed IB. The flesh browning was sorted into 5 classes $(0-$ 4) according to Ezzat et al. (2017). Then an IB index was calculated.

\section{Total phenol content measurements}

Total soluble phenols were determined by Folin-Ciocalteu's (FC) reagent (Sigma- Aldrich). Total phenolic contents were determined using the FC reagent according to Singleton and Rossi (1965). Fruit extract solution $(40 \mu \mathrm{l})$ were added to $1.8 \mathrm{ml}$ of FC reagent. The 10 times prediluted reagent was used. Total soluble phenols were presented on fresh weight (FW) as mg gallic acid equivalents (GAE) for $100 \mathrm{~g}$ (GAE/100 $\mathrm{g} \mathrm{FW}$ ).

\section{Ployphenol oxidase (PPO) activity}

PPO was determined by $1.0 \mathrm{~g}$ fresh tissues which was freezed and homogenized in $5 \mathrm{ml}$ of sodium phosphate buffer which contain $1 \%$ polyvinylpyrrolidone. The active was expressed as one unit of PPO was able to raise the absorption by 0.01 at 410 $\mathrm{nm}$ in $1 \mathrm{~min}$. The PPO activity was expressed as $\mathrm{U} \mathrm{g}^{-1} \mathrm{FW}$.

\section{Results and discussion}

\section{MJ and hot water treatments for total acceptance of apricot fruit}

The total acceptance of the fruit was affected by the treatments and the storage time (Table 1). The total acceptance of the fruit was decreased with the storage time for the untreated fruit which showed reduction in the acceptance from the $2^{\text {nd }}$ day at room temperature to be very low at the $10^{\text {th }}$ day meanwhile the MJ and hot water treated fruit showed the best results in compare to control treatment. The treated fruit with MJ showed better results than hot water treated fruit. After 8 days at room temperature the total acceptance was 3.89, 3.00 and 0.68 for MJ, hot water and control fruit, respectively. The same trend was noticed for internal breakdown data, both hot water and MJ fruit showed resistance to IB till the day 4 of storage in compare to untreated fruits.

Table 1. Effects of different post-harvest treatments on total acceptance and internal breakdown of apricot at shelf life (MJ: methyl jasmonic acid).

\begin{tabular}{lcrrr}
\hline \multirow{2}{*}{ Measurements } & Assessment & \multicolumn{3}{c}{ Treatments } \\
\cline { 3 - 5 } & time (Days) & Control & MJ & Hot water \\
\hline \multirow{3}{*}{ Total acceptance of } & 0 & 4.98 & 4.87 & 4.92 \\
the fruit & 2 & 4.10 & 4.59 & 4.34 \\
& 4 & 3.01 & 4.24 & 3.98 \\
& 6 & 2.26 & 4.01 & 3.68 \\
& 10 & 1.56 & 3.89 & 3.00 \\
Internal breakdown & 0 & 0.68 & 2.87 & 2.21 \\
& 2 & 0.00 & 0.00 & 0.00 \\
& 6 & 1.28 & 0.00 & 0.00 \\
& 8 & 2.25 & 0.00 & 1.22 \\
& 10 & 3.25 & 1.58 & 2.21 \\
& & 4.00 & 2.00 & 2.98 \\
\end{tabular}

At day 10 of storage at room temperature the untreated fruits showed the maximum IB meanwhile MJ and hot water treated fruit showed better results (2.98 and 3.14, respectively). The effect of using some elicitors like 0.2 and $2 \mathrm{mmol} / \mathrm{L}$ methyl jasmonate and salicylic acid, respectively, on apricot fruits showed enhancement in all sensory properties after storage and shelf-life (Ezzat et al., 2017). Some features like sugars and organic acids contents are correspond to several sensory features of apricot fruits. The degradation of some polysaccharides into other simple elements was demonstrated to be one of the reasons for the decrease of fruit taste during storage (Colaric et al., 2005; Ezzat et al., 2013).

\section{Effect of MJ and hot water treatments on SSC of apricot fruit at room temperature}

Data in Figure 1 showed that the effect of treatments on the apricot SSC helped to keep high SSC of the fruit at shelf life in compare to untreated fruit. There was an increase in SSC in all treatments till the $8^{\text {th }}$ day at room temperature. This increase was higher in MJ than Hot water treated fruit while untreated showed the less values of SSC in all assessment times. Our finding is matched with Ezzat et al. (2017) in apricot fruit when it treated with $\mathrm{f} 0.2 \mathrm{mmol} / \mathrm{L}$ and $2 \mathrm{mmol} / \mathrm{L}$ methyl jasmonate and salicylic acid, respectively. Also this was reported in Canino apricot in Egypt (Shemy, 2020).

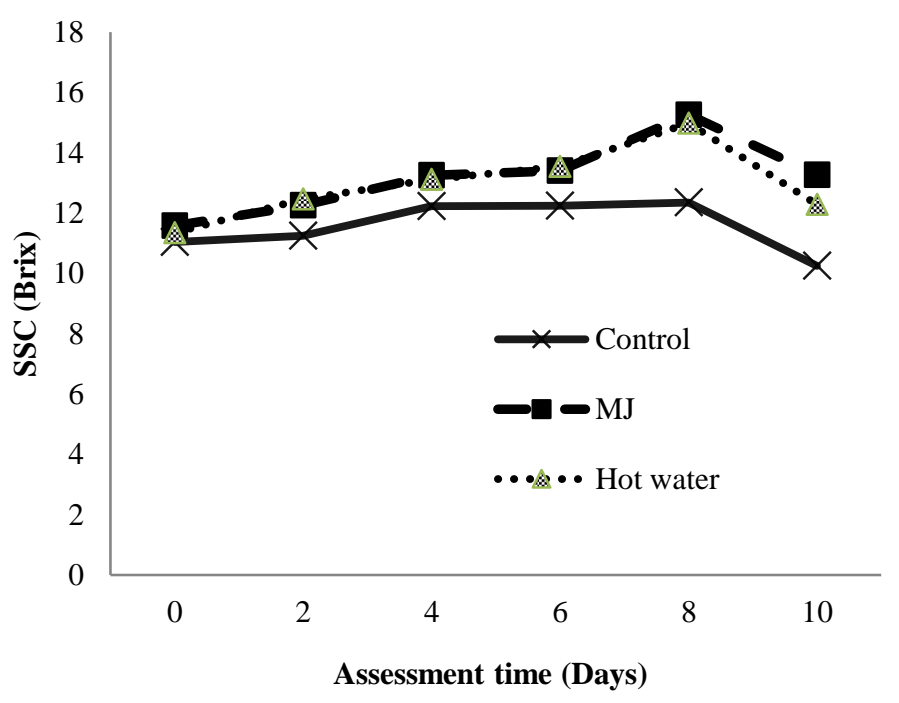

Figure 1. Effects of different postharvest treatments on soluble solid concentration (SSC) of apricot fruits during storage at room temperature (MJ: methyl jasmonic acid).

\section{Effect of MJ and hot water treatments on fruit firmness of apricot fruit at room temperature}

Fruit firmness was decreased with storage time in all treatments (Figure 2). The reduction in fruit firmness was obvious in untreated fruits especially at the $4^{\text {th }}$ day in shelf at room temperature then there was a dramatic reduction till the $10^{\text {th }}$ day. For MJ treated fruit the reduction was not dramatic till the $8^{\text {th }}$ day and even at $10^{\text {th }}$ day of storage at room temperature still MJ fruit recorded high firmness than untreated by $2.5 \mathrm{~kg} . \mathrm{cm}^{2}$. The same trend was reported for hot water treated fruit but the MJ fruit showed better results at $4^{\text {th }}, 6^{\text {th }}$ and $8^{\text {th }}$ day of assessment. During fruit ripening, firmness loss occurred, which is an essential element limiting postharvest stage. Various firmness values during ripeness were detected in different 
cultivars (Ezzat et al., 2012). The same trend was reported in apricot fruit when they stored in modified atmosphere packaging (Ezzat, 2018) they showed that untreated fruit recorded sever reduction in fruit firmness while MAP treated fruit showed more harder fruit over the storage period. Fruit firmness showed relation to the maturity of the fruit at harvest time, the firmness reduced with a later harvest of tested varieties (Ezzat, 2019).

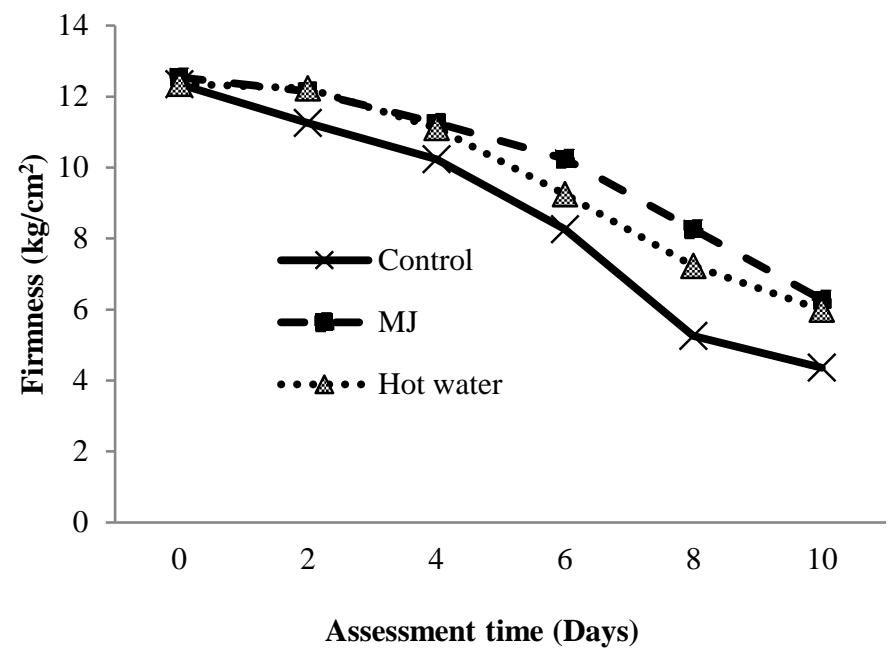

Figure 2. Effects of different postharvest treatments on firmness of apricot fruits during storage at room temperature (MJ: methyl jasmonic acid).

\section{Effect of MJ and hot water on weight loss of fruit at room temperature}

During the storage of fruit at room temperature all the treatments showed weight loss (Figure 3.). The reduction in weigh was significantly higher in untreated fruit than MJ and hot water treated fruit. The lowest weight loss was recorded in the $\mathrm{MJ}$ treatments in compare to control and hot water treated. It was reported that $0.2 \mathrm{mmol} / \mathrm{L} \mathrm{MJ}$ decreased water loss of apricot fruit during storage and shelf-life (Ezzat et al., 2014, 2017). Weight loss of apricot was in good relation to long storage and over maturity of fruit (Ezzat, 2019). Similarly to our study, the MJ treatment $(16 \mu \mathrm{mol})$ could decrease the loquat weight loss after a 35-day storage at $1{ }^{\circ} \mathrm{C}$ with a 3-day shelf-life storage at $20^{\circ} \mathrm{C}$ (Jin et al., 2014).

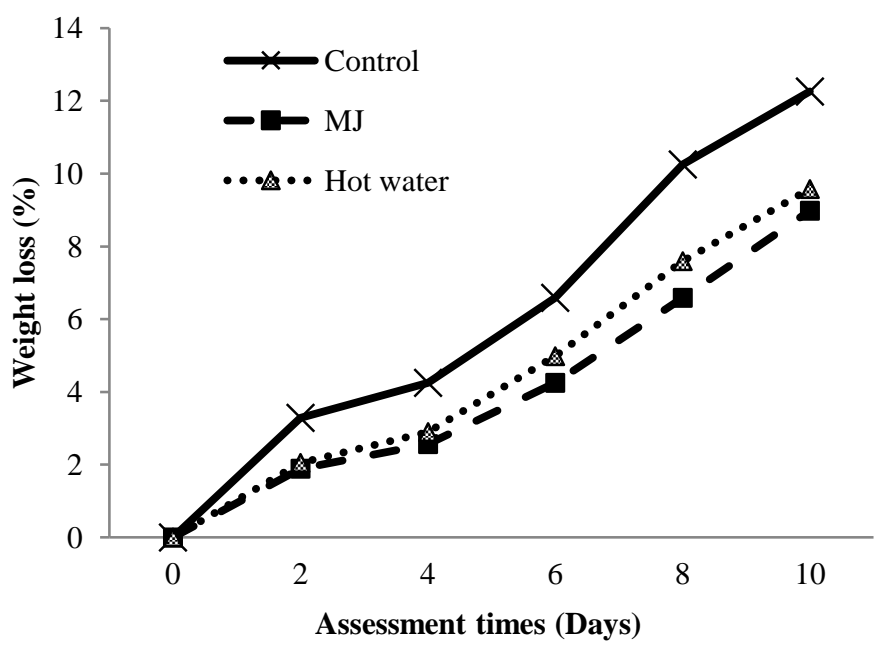

Figure 3. Effects of different postharvest treatments on weight loss of apricot fruits during storage at room temperature (MJ: methyl jasmonic acid).

\section{Effect of MJ and hot water treatments the total phenolic content of fruit at room temperature}

The total phenolic content for control fruit reduced during storage (Figure 4). Meanwhile, MJ and hot water treated fruit, showed increase in total phenol content until the $4^{\text {th }}$ day then reduced. In all assessment times the total phenol content of control fruit had the lowest values in compare to other treatments. Results of this study are in agreement with findings of Ezzat et al. (2017) indicating that SA increased the activity of antioxidant capacity of apricot fruit during storage or shelf life.

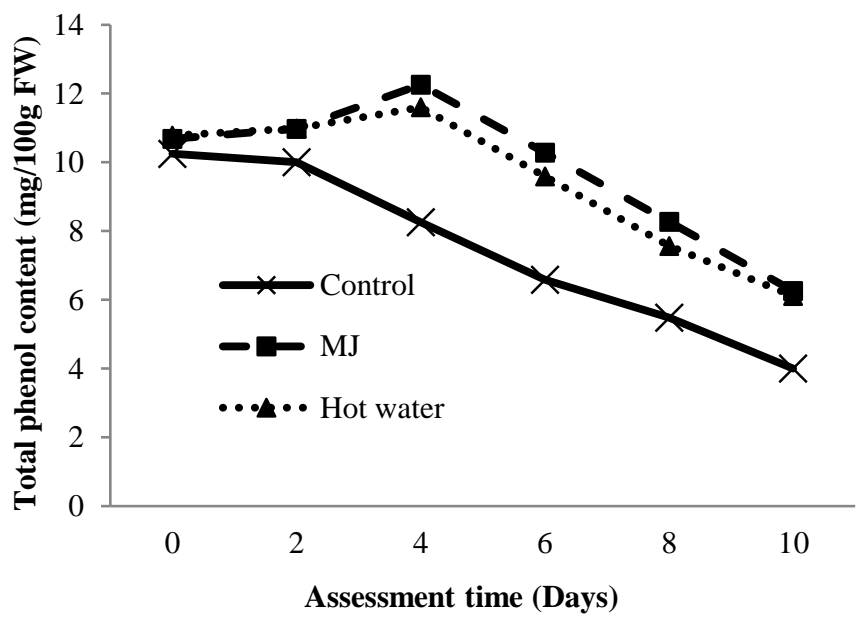

Figure 4. Effects of different postharvest treatments on total phenol content of apricot fruits during storage at room temperature (MJ: methyl jasmonic acid).

\section{Effect of MJ and hot water treatments the PPO activity of apricot fruit at room temperature}

The PPO activity increased gradually in all treatments and control fruit showed the highest values in compare to other treatments (Figure 5.). The untreated fruit showed the significance increase and reach to the maximum at the $6^{\text {th }}$ day of storage meanwhile other treatments reached to maximum at the $8^{\text {th }}$ day then start to reduce.

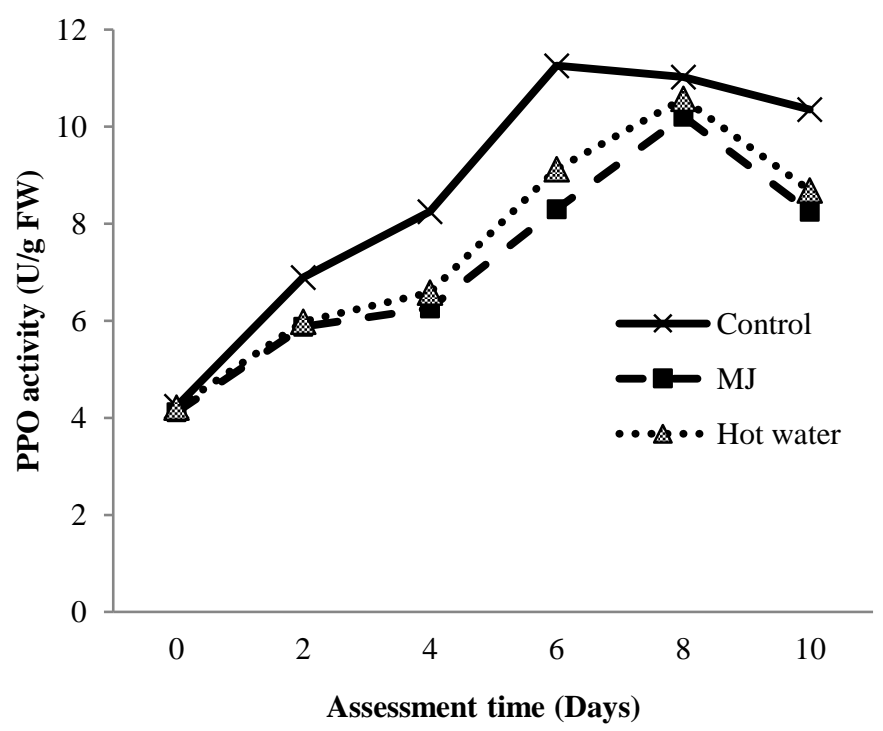

Figure 5. Effects of different postharvest treatments on ployphenol oxidase (PPO) activity of apricot fruits during storage at room temperature (MJ: methyl jasmonic acid). 
It was reported that PPO mediated oxygenation of phenols content and this resulted in producing some browning substances in fruit and vegetables (López-Serrano \& Ros Barceló, 1999). The browning of fruit was found related to both phenol content and PPO activity (Ezzat et al., 2013, 2014; Wu et al., 2015). Our finding results indicated that total phenolic content showed reduced values with the storage time, while the activity of PPO first raised and then declined. The same trends were shown by Guo et al. (2011) who demonstrated that a rise in the consumption of phenols is coupled with increasing PPO activity during storage.

\section{Conclusions}

The results supported the idea of using some elicitors like methyl jasmonic acid and hot water treatments to induce more fruit resistance to internal breakdown and enhance shelf life of the fruit.

\section{References}

Amiri, A., Holb, I. J., Schnabel, G. (2009): A new selective medium for the recovery and enumeration of Monilinia fructicola, M. fructigena, and M. laxa from stone fruits. Phytopathology, 99(10), 1199-1208. doi: 10.1094/PHYTO-99-10-1199.

Cao, J. K., Zhao, Y. M., Wang, M., Lü, H. Y., Jiang, W. B. (2009): Effects of 1-methylcyclopropene on apricot fruit quality, decay, and on physiological and biochemical metabolism during shelf-life following long-term cold storage. Journal of Horticultural Science and Biotechnology, 84(6), 672-676. https://doi.org/10.1080/14620316.2009.11512584

Colaric, M., Veberic, R., Stampar, F., Hudina, M. (2005): Evaluation of peach and nectarine fruit quality and correlations between sensory and chemical attributes. 2616(August), 26112616. https://doi.org/10.1002/jsfa.2316

Ezzat, A. (2019): Apricot fruit chilling injuries during the cold storage affected by harvest maturity. International Journal of Horticultural Science, 25(3-4), 28-31.

Ezzat, A., Amriskó, L., Mikita, T., Nyéki, J., Soltész, M., Szabó, Z. (2012): Variation between some apricot varieties in regard to flowering phenology in Boldogkőváralja, Hungary. International Journal of Horticultural Science, 18(1), 7-9.

Ezzat, A., Nyéki, J., Soltész, M., Amriskó, L., Balázs, G. I., Mikita, T., Szabó, Z. (2012): Storability of some apricot varieties as affected by storage period. International Journal of Horticultural Science, 18(1), 39-42.

Ezzat, A., Szabó, Z., Ammar, A. K. (2014): The role of some elicitors in inducing chilling stress resistance in apricot fruit. Acta Agraria Debreceniensis, (59), 27-32.

Ezzat, A., Szabó, Z., Nyéki, J. (2014): Induce the plant resistance to pathogen infection. International Journal of Horticultural Science, 20(1-2), 89-93.

Ezzat, A., Szabó, Z., Nyéki, J., Holb, I. J. (2013): Preliminary results on salicylic acid treatment on brown rot caused by Monilinia laxa on Jumbo Cot fruit, Prunus armeniaca L. International Journal of Horticultural Science, 19(3-4), 37-39.

Ezzat, A. (2018): Effect of modified atmosphere package on apricot fruit storability. International Journal of Horticultural Science, 24(3-4), 30-32.
Ezzat, A., Ammar, A., Szabó, Z., Holb, I. (2017): Salicylic acid treatment saves quality and enhances antioxidant properties of apricot fruit. Horticultural Science, 44(2), 73-81.

Ezzat, A., Ammar, A., Szabó, Z., Nyéki, J., Holb, I. J. (2017): Postharvest treatments with methyl jasmonate and salicylic acid for maintaining physico-chemical characteristics and sensory quality properties of apricot fruit during cold storage and shelf-life. Polish Journal of Food and Nutrition Sciences, 67(2), 159-166.

Guo, Q., Cheng, L., Wang, J., Che, F., Zhang, P., Wu, B. (2011): Quality characteristics of fresh-cut "Hami" melon treated with 1-methylcyclopropene. African Journal of Biotechnology, 10(79), 18200-18209. https://doi.org/ 10.5897/AJB11.2439

Holb, I. J. (2004a): The brown rot fungi of fruit crops (Monilinia spp.): II. Important features of their epidemiology. International Journal of Horticultural Science, 10(1), 17-33.

Holb, I. J. (2004b): The brown rot fungi of fruit crops (Monilinia spp.): III. Important features of disease management. International Journal of Horticultural Science, 10(4), 31-49.

Holb, I. J., Schnabel, G. (2007): Differential effect of triazoles on mycelial growth and disease measurements of Monilinia fructicola isolates with reduced sensitivity to DMI fungicides. Crop Protection, 26(5), 753-759. https://doi.org/ 10.1016/j.cropro.2006.07.001

Holb, I. J., Schnabel, G. (2008): The benefits of combining elemental sulfur with a DMI fungicide to control Monilinia fructicola isolates resistant to propiconazole. Pest Management Science, 64(2), 156-164. https://doi.org/10.1002/ps.1492

Holb, I. J., Scherm, H. (2008): Quantitative relationships between different injury factors and development of brown rot caused by Monilinia fructigena in integrated and organic apple orchards. Phytopathology, 98(1), 79-86.

Jin, P., Duan, Y., Wang, L., Wang, J., Zheng, Y. (2014): Reducing Chilling Injury of Loquat Fruit by Combined Treatment with Hot Air and Methyl Jasmonate. Food and Bioprocess Technology, 7(8), 2259-2266. https://doi.org/10.1007/s11947-013-1232-3

López-Serrano, M., Ros Barceló, A. (1999): H2O2-mediated pigment decay in strawberry as a model system for studying color alterations in processed plant foods. Journal of Agricultural and Food Chemistry, 47(3), 824-827. https://doi.org/10.1021/jf980576w

Manganaris, G. A., \& Crisosto, C. H. (2020): Stone fruits: Peaches, nectarines, plums, apricots. In Controlled and Modified Atmospheres for Fresh and Fresh-Cut Produce. https://doi.org/10.1016/b978-0-12-804599-2.00017-x

Shemy, M. A. El, \& Shemy, M. A. El. (2020): Effect of some essential oils, salts and salicylic acid on reducing decay, keeping quality and prolonging shelf-life of canino apricot fruits. Menoufia J. Plant Prod, 5, 111-128.

Wang, H., Wu, Y., Yu, R., Wu, C., Fan, G., Li, T. (2019): Effects of postharvest application of methyl jasmonate on physicochemical characteristics and antioxidant system of the blueberry fruit. Scientia Horticulturae, 258 https://doi.org/10.1016/j.scienta.2019.108785

Wu, B., Guo, Q., Wang, G. xia, Peng, X. yuan, Wang, J. de, Che, F. bin. (2015): Effects of different postharvest treatments on the physiology and quality of 'Xiaobai' apricots at room temperature. Journal of Food Science and Technology, 52(4), 2247-2255. https://doi.org/10.1007/s13197-014-1288-8 